\title{
Creative Life of Ye. I. Zverkov: Evolution of Landscape Painting in Russia in the Second Half of the $20^{\text {th }}$ Century
}

\author{
Lyubov Shirshova \\ Department of Humanitarian Discipline \\ Russian State Specialized Art Academy \\ Russian Academy of Arts \\ Moscow, Russia \\ E-mail: 1shirshova@.rah.ru
}

\begin{abstract}
This article focuses on the art landscape of Ye.I. Zverkov, a prominent painting master, a People's Artist of the USSR, academician of the Russian Art Academy, State Prizes winner. This review expands the range of interpretations of the artist's creative work and reveals new aspects of his landscape painting of the second half of the twentieth century. On the basis of creative work of E.I. Zverkov the author analyses evolution of the national landscape of the second half of the twentieth century as the development and renewal of creative tradition and discovers key features of landscape painting in the period of the Khrushchev "Thaw".
\end{abstract}

Keywords-period of formation; national academic school; time of "Thaw"; "grim style"; "Russian impressionism"; traditions in art; realism

\section{INTRODUCTION}

In the recent decades, the Russian society does show a sustained interest in national heritage traditions and the need to understand the origins and ways of development of the modern art of landscape.

Native of the Tver Territory Yefrem Ivanovich Zverkov (1921-2012), a people's artist of the USSR, academician, State Prizes winner, has made a significant contribution to the development of the national landscape painting. His name by right is among the greatest painters of his day. He is a master who created its own deeply lyrical direction of the national landscape. Huge artistic charm and individuality of his works and their national identity allow us to speak about the artist's creative work as a big phenomenon in the history of fine art.

Ye. I. Zverkov was one of the leaders who had been breaking a new ground in the national art in the 1960s that changed aesthetical views and the system of artistic values. As an integral artistic personality with the talent of foreseeing he has determined the development of landscape and Russian impressionism, enriched the fundamentals of the Moscow School of Painting, became the leading representative of this unique direction. By investigating Zverkov' deep and complex art we can see the evolution of the national landscape painting of the second half of the twentieth century. And the more this era goes away, the clearer and more sophisticated the sense and imperishable art authenticity of the artist's discoveries are. The best Zverkov's works are included by right into the classic and are presented in the collections of the Tretyakov Gallery, the State Russian Museum and over 40 museums of Russia as well as various collections in many countries of the world. His creative work is the basis for development of the national art school.

\section{YEARS OF GAINING PROFESSIONAL EXCELLENCE}

Yefrem Zverkov belongs to the generation whose youth was tempered by the Great Patriotic War (1941-1945). The ordeals of war influenced the formation of ideology and the system of universal human values and views toward art.

It is worth to note that the master's creative work is based upon the synthesis of Petersburg and Moscow schools of art. Prior to the Great Patriotic War, in Tver Yefrem Zverkov studied from Nikolay Borisov, a graduate of the Imperial Academy of Art, the workshop of great Ilya Repin. In his turn, Repin owes his professional education to the national academic school and the famous teaching system of P.P. Chistiakov. By rethinking the traditional forms and methods of his time, Chistiakov was able to develop a fundamentally new school that raised outstanding artists of the second half of the nineteenth century and the beginning of the twentieth century. His method helped to raise not only a skillful artist but a creative artist as well. Conventionality is a distinctive basis of the academic school. Thus, Ye.I. Zverkov who studied at the N.Ya. Borisov's workshop and subsequently at the All-Russian Academy of Art in Leningrad (1939, currently Saint Petersburg) has mastered a special academic system teaching how to draw. As a separate teaching discipline, the academic drawing has always been the very essence of the academic school of Russia.

Another principal foundation of the school was a close link to nature. It is worth to note that Zverkov was skilled in drawing. Many of his works are in the collection of the Scientific and Research Museum of the Russian Academy of 
Art. At the Sourikov Moscow Art Institute, the artist has completed a good professional training on drawing and painting and became able to fulfill complex technical tasks. Moreover, the generation of Zverkov was educated in accordance with the assumption that "a thinking artist is the supreme type of artist". At the same time, Zverkov as a painter who was perfect in academic drawing later took it to a great extent as a preparatory work.

The line of succession of historical and cultural tradition in art connected Zverkov's creative work with the Moscow school of painting that was successfully completed by him in the period of this training in Moscow. In 1946, Zverkov was admitted to the Moscow Studio established by the Academy of Art of the USSR (now the Russian Academy of Art), the workshop of academician B.V. Johanson, a prominent painter. The influence of this studio on the artist's life cannot be overemphasized. B.V. Johanson was a vivid creative personality, and for him an ideal painter was his teacher K.A. Korovin. Like his mentor, in his teaching practices he used the method of emotional understanding of picturesque harmony of nature and called his learners to the integrity of vision and the unity of the whole order of color and tone relations. In the Studio, Zverkov began joining in the Moscow painting tradition. At the end of his first study year, Zverkov began to stand out among other students as a subtle colorist talented in making compositional arrangements that was noted by Johanson who highly appreciated his brilliant academic work "Tsyganka/Gipsy" (1946). His studentship at the Sourikov Art Institute (1947-1953) included intensive mastering the skills of painting, close inspecting the collections of Moscow museums, deep investigation and imitation of works by great masters of the past, and comprehension of art of his outstanding contemporaries at numerous art exhibitions.

A.A. Plastov, a prominent painter, has played an important role in the beginning of Zverkov's creative career. Plastov and Zverkov are the two names that celebrated the national art. They met in Moscow in 1947. Ye.I. Zverkov studied at the institute together with A.A. Plastov's son. The great artist was in the heyday of his glory, and the future landscape painter just started his creative journey, but despite the disproportion in their age, they had been friends for many years. The underlying principle they were developing in their art was direct work with outdoor scenes, and the landscape as the origin of artistic energy.

Plastov was a wise mentor and told a lot about his attitude to creative work, tasks of an artist, the fundamentals of the artistic perception of the world. Showing deep respect to his great mentor, Zverkov selectively applied the creative experience of the former aiming to find his own way in art. The artist has always tended to inner freedom. It was the freedom that allows comprehending and understanding the world around and ensures the mastery of painting.

\section{EARLY PERIOD OF THE ARTIST'S CREATIVE WORK}

Ye.I. Zverkov devoted the last years of studentship and the first years after graduation to the creation of the narrative picture. His deep desire to tell about his generation that survived the war has determined Zverkov's spiritual impulse for his work in that period. In Zverkov's genre painting, the action is always submerged in nature. He saw in the organic unity between man and nature the conditions of forming the moral foundation of the human personality. It is always pictorially rich harmonic environment that helps to disclose the substance of the subject matter.

During those years, the landscape interpretation of genre pictures was combined for the artist with working on pure landscape in that he created heartfelt and meaningful images of the Russian land. Ye.I. Zverkov's attitude to nature is a special philosophy of life. The artist was a war veteran and has seen many tragic events, and timeless values such life or nature were highly regarded by him. As early as in the student years, Zverkov's individual method has started to form. He used impressionistic tools and techniques more freely and spontaneously than many painters of his generation did. It was an uncommon artist, who paid much attention to drawing and landscape compositional arrangements.

He treated the poetry of vision as a way to understand himself and his place in life and as an awareness of infinity of ties with the entire universe. The contemporaries called him the founder of "a contemplating landscape" [1]. The main feature of his art has always been realistic. Zverkov has been developing with dedication new artistic expressive means. He discovered original features of his talent early in life. His tender love towards his mother nature of Central Russia has become an inexhaustible life blood that determined his artistic destiny.

From an early age and for the whole of his artistic career, Ye.I. Zverkov has been painting sketches. His feeling of nature gave an emotional impulse to his painting and filled it with a vivid and tender sense. For him the color and the tone are the visualization of the world, the color itself, sun and air. He makes experiments trying to improve the expressiveness of the landscape vision. Leaving three or four colors in the palette, he paints with large splashes with a fine color working out within their area, disclosing the richness of tones and a great variety of shades within a splash (The Beginning of Spring, 1953).

Improving his landscape painting Zverkov has always drawn a lot, closely reviewing and exploring an outdoor scene. Numerous quick sketches of landscape motives helped to better understand the form of a tree, the outlines of a riverside and a distant village on a hill. In that period, he was enthusiastic about watercolor techniques. Watercolor painting gradually added complexity to the color system, helped to discover an inexhaustible richness of nuances and shades and to develop a transparent and soft musical brushstroke. In that period, no less important than working on genre pictures was the portrait painting. Zverkov has never painted custom-made portraits. The artist painted on his canvasses the characters of his pictures and his family members. He created many self-portraits. Still life is a constant component of the artist's creative work. Observing the beauty in simple things, he constantly sought the painting integrity, expressiveness and fullness of each form. 
However, it is the landscape painting where Zverkov showed his peculiar creative individuality to the most extent.

\section{PERIOD OF THE KHRUSHCHEV'S "THAW"}

After I.V. Stalin's death (1953), rapid political developments began. The time of Khrushchev's "Thaw" gave rise to the process of liberalization in the area of art. Thanks to young painters who actively and brilliantly entered the creative life of the country in the 1950s, a new period of cultural development began, artistic orientations changed, and various style directions in art appeared. The process of new imaginative comprehension of the world covered all spheres of creation, all types of art - music, cinema, theater literature; artists wished to get in touch with the truth of life more closely.

A creative personality became more active. People of art sought the expertise of the national and global culture more easily. The process of learning traditions developed in different ways. The sixtieths are often associated with the art movement characterized by a publicistic focus that later will be named "the grim style". In its creative development, it leaned against the experience of the domestic associations of the 1920s such as "The Society of Easel" (OST), "Jack of Diamonds", "Four Arts". Artists of the 1960s perceived the principles of art in the beginning of the twentieth century, a genetic link of eras as the comprehension of a spiritual essence of old traditions, an artistic device or an expressive means to realize their ideas. Young artists moved away from certain clichés of the art and imagery system of the socialist realism and sought for new formal expressive means to renew the figurative and plastic language of painting that are capable to reflect deeply the spiritual world of modern man.

Actually, new aesthetic principles were forming. On the cusp of the 1950s and 1960s, the art of Russian impressionism was not left behind the mainstream of changes. In that period, Yefrem Ivanovich Zverkov has made six long journeys on the Russian North. The creative work in the North helped him to become one of the first expressers of "the grim style" in the landscape painting. The artist creates a monumental canvas "The New Boat" (1961, the State Tretyakov Gallery). In the foreground, on the bank of wide northern river Mezen warmed up by the sun, a shining goldish boat standing on the stage can be seen behind which there are dark and cold waters and the far side covered with forest.

The landscape expressiveness is provided by the largescale spatial solution, thought-out compositional arrangements, color resonance and a special luminescence of painting. A significant spiritual content of this work of art allows to reflect the time. Canvas "The New Boat" filled with a severe poetry and romantic triggers universal associations with the renewal and perpetual movement of life. The basis for the connection between human actions and the image of nature in the Russian tradition has always been the conception of landscape as the fate of the country. In the artist's landscapes of the "thaw" period, key means of artistic expression such as color, tone system principles, composition have changed. New features of world perception and new methods of artistic expression thereof were forming. At the same time, his art had common features that determined the essence of the process of landscape development of that time.

However, the art evolution in the sixtieth was not entirely characterized by the notion of "the grim style". There were artists of new generation who had a direction in their creative work connected with the development of the Russian impressionism and oriented to the art of members of the Union of Russian Artists. "Shestidesyatniki" noticed in the culture at the cusp of the 19th - 20th centuries a substantial artistic potential that could enrich the modern art by opening the way to understanding the national reality as a historical process. The Russian impressionism of the period of Khrushchev's "thaw" comprises the searches and discoveries of new means of artistic expression for reflecting the ideas of the time more thoroughly.

Ye.I. Zverkov as a master of lyrical landscape became the leader of the Moscow group. He was able to bring a fresh momentum with this creative work combining the national traditions with the original author's new style. Working out the impressionist painting principles, he experimented a lot inspiring in the others the creative spirit of the time and recognizing that such new artistic situation paves the way for a freer self-expression. His northern journeys facilitated fast and material changes in Zverkov's art. The painter was charmed by a primitive beauty, majesty and mightiness of the North that created a different perception of space. Deep understanding by Zverkov of the northern nature led to creating by him a great cycle of "pure landscapes". He brought into these works of art an elevated sense of worship and admiration of mighty nature. The artist's emotional perception of the world was refracted in deep synthesized pictures of nature. The composition was arranged with several grounds based on majestic and slowed rhythm. In his landscapes of the North, he seemed to cover by the panoramic vision a huge space of earth and sky. The innovation of Zverkov's northern landscapes was expressed in his space and compositional solutions, the diversity of emotional characteristics and emotional content of his works.

For those years, Ye.I. Zverkov's style has acquired more general and monumental elements. The integrity in perceiving the beauty of nature in spring distinguishes one of his well-known landscapes - "The Northern Spring" (1969) kept in the collection of the Tretyakov Gallery. The artist has clearly captured the elements of spring flood - an endless space of the river. Still there is an extraordinary cosmic panorama effect of the landscape in the vastness of water space and the immensity of cloudy sky. The artistic comprehension of the compositional arrangements, rhythm and harmony seeks to capture the triumph of the bright side of the universe. The artist uses color to combine everything into an integrated whole. The colors of sky are reflected in water space vastness. The azure of the wide river waters merges into light infinite sky. The means of painting capture the state of spring freshness and humidity of air. Everything in this picture is filled with a sense of silence, harmony as if a great balance in forces of nature were achieved. The philosophical spirit of the universe dominates over all other 
feelings. In this work of art, the painter goes to as high as the symbolic generalization.

The modernity of contents and the modernity of artistic language were achieved by hard work and discoveries. The second part of the 1950s and 1960s was for Zverkov the time of forming his own creative image. In those years, a specific conventionality in artistic language of the painter's works has arisen based upon deep knowledge of the painting laws of depiction. A poetic conventionality, color metaphor in Zverkov's creative work are complex notions; and they are expressed not only in the amount of painting and plastic techniques reflecting an emotional projection of the objective world, but also in the original creative thinking of the artist who perceived the concrete nature of real phenomena and images as the aggregate of poetic associations.

The period of "thaw" is just a short time interval. Nevertheless, it became a major phase in the history of art culture in our county. The painting at the time of "thaw" tends to become a global phenomenon. Reviewing creative work of leading painters of that time seems to be certainly relevant.

In the 1960s, the national landscape painting has been given a powerful impetus for development as the area of spiritual life of the society and has become one of the main forms of painting. Priority was given to a trend to create generalized philosophical pictures of epical nature. This art of landscape was largely promoted by Zverkov's versatile creative work. He discovered new prospects of the Russian impressionistic painting based upon its own artistic understanding of nature and his new graphic means. In his works, the painter went from a poetic expressiveness of the motive to an epical generalization of the vision of nature. For Zverkov, landscape is not a reproduction of an outdoor scene, but its representation or reflection of his individual perception, the result of his meditations, his learning of the world through his art. His landscapes are always filled with deep meaning and metaphors.

\section{TIME OF ARTISTIC MATURITY}

There comes the time of artistic maturity. The artist has become fully oriented. He approached to such a state of freedom in his creative consciousness when a certain natural phenomenon would determine a work of art with a unique artistic solution. In their book "The Soviet Painting", known art critics A.V. Paramonov and S.M. Chervonnaya point out that "in each of four seasons of the Russian land, Zverkov finds its own unique beauty and poetry, and there is no stereotype in his poetical treatment of the world, and the thrill of a discoverer is felt everywhere" [2].

Art works of that time have a deeply individual interpretation of landscape visions. The foreground was being outlined easily and freely as if it were missed and the focus moved further to delicate contours of a river or forest or a lonely big tree. The main impression here was created by a harmonic combination of color splashes of various saturation giving a sense of rising morning mist or humid spring air. Zverkov's light-colored palette enriched by a complex system of nuances, half-tints, reflexes showed nature with light and air running through it ("The Silence" (1972), "The Lonely Apple-Tree" (1973), "The Early April" and others).

In art works of that time there was growing interest to plastically movable images. The issues of rhythm and space became more complicated. Zverkov assured a specific vivification of nature existence by conveying difficult states of nature such as early quiet dawns, spring dusk, and autumn days with the air wet from rain. Mist and humidity create the most delicate and rich color palette in the atmosphere, make softer the contours of trees and buildings and convey a special emotional state in nature. Each landscape transforms from an outdoor scene into an original inspired vision ("The Drops of Rain", "The Heavy Shower" (1974) and others).

There are no people in the artist's landscapes. He believed that nature is able to convey the thoughts and feelings of the author. The silence of harmony, philosophic contemplation, spiritual intensity of Zverkov's art works provide for an incredible abundance of feelings, thoughts, associations, metaphors ("The Quiet River" (1970), "The Summer Twilight" (1972) and others).

During the 1970-1980s, the landscape painting has continued to diversify in styles. The most dynamic was lyrical landscape in the creative work of A.M. Gritsai, N.M. Romadin and others. Romantic disposition in images of nature associated with high degree of decorative expressiveness can be seen in works of G.G. Nisskiy, B.F. Domashnikov, T.T. Salakhov and others. Such artists as O.N. Loshakov, Ya.Yu. Kryzhevskiy and others painted landscapes of philosophic and symbolic character.

Ye.I. Zverkov shows himself as a multifaceted artist; he is an insightful lyric who can convey the poetry of man's feelings, a deep and wise philosopher trying to comprehend and show in his works the philosophy of the laws of the universe, a romanticist creating deeply emotional works.

An infinite diversity of motives can be seen in the artist's works filled with emotional and romantic content ("Before a Thunderstorm" (1969), "The Rainbow" (1974), "The Indian Summer" (1993), "Autumn. Thunderstorm" (1998) and others). Using the sharpness of his vision, the artist makes spatially expressive compositions giving a monumental character to unusual images of nature.

Searching for art expressive means capable to disclose and convey the lyrism of feelings, Zverkov achieves in his works a specific melodiousness. Being perfect in the impressionistic technique of separate brush stroke, he filled his landscapes with fluid and quivering light that seemed to be consonant with eternal space and time flow. ("Autumn. Belov Ravine" (1965), "Autumn Time" (1970), "First Green" (1974), "Spring in Forest" (1975) and others). Such kind of painting required the artist's inner harmony so that he could harmonize the sounding of pure colors with his quick and gentle brush stroke. The world around was becoming sparkling, transparent, fragile, dependent on eternal change in light and color.

The artist's coloristic talent enabled him to reach a special spirituality of color. Zverkov's painting being gentle and fine 
in coloration brings with it a poetic metaphor in the very color system of his works. The rhythm of brush strokes in his landscapes is melodious and they make the plastically perfect canvas surface a self-important part of the landscape pattern. In his well-known picture "Thin Birches" (1971), the image of white-trunked young birches in a light cloud of coming out green leaves on the sunny hillock is similar to a tender song about the youth that is light and fragile in its vulnerability. The artist masterfully conveys the superfine play of shadow color and light.

Landscape discloses the multifaceted wealth of Zverkov's artistic talent. Art critics and artists write about the painter's creative work as "a significant phenomenon in fine art" [3]. Many authors note a specific transparency of silvery tonality of the artist's works and typical for his landscapes "unexplainable harmony and silence" [4]. The completion of a certain creative period for an artist is the time for summing-up and exhibition of works. At his large-scale personal exhibition arranged in the galleries of the Moscow Union of Artists at Kuznetsky Most in 1975, Zverkov acted as a matured artist with his own style called by right "the Zverkov's style". His art works created for twenty years generated great interest. Zverkov's name became widely known. It became a synonymous with the sincerity and lyricism in landscape painting. Since that time, Zverkov's fame has become global and he was invited as a participant to numerous foreign exhibitions.

The contemporaries emphasized that in the area of lyrical landscape "the greatest representatives in the Russian painting were such artists as A.M. Gritsai, N.M. Romadin, Ye.I. Zverkov, B.F. Domashnikov" [5].

During the 1980 - 1990s Zverkov who was perfect in using all painting means has narrowed his color palette and nearly excluded the whitewash and started to paint more decoratively [6]. His individual manner of painting has changed becoming more wide and general. A different painting vision was achieved by decorative simplification of painting means ("The Distant Chapel" (1990) and others).

In the artist's works, the complexity of rhythmical interpenetration created the sense of space changeability. The spontaneity provided by tense watchfulness was combined with a clear structural order of composition and the generalization; and an original melodiousness arose. For example, it can be seen in landscape "The Golden Evening" (1995) showing the bank of river Osetr in that rare time of day when the last ray of sun lights up the quiet earth, still waters of the river and robust woods on the bank. All the surface of the work with its fused colorful big areas flows together into a magnificent and solemn melody.

Zverkov's art had been constantly developing. He was blessed with the ability to feel the process of life, its eternal movement and renewal. On the cusp of the twentieth and the twenty-first century, we can see in the artist's creative work a trend to create epical philosophic landscapes and generalized vision of nature of Central Russia, and to unfold the dynamic space of its image and to use the panoramic principle in the outlay of his works ("Russian Vastness" (1998), "Spring Sky" (2003), "Zaraisk Land" (2003) and others).
Undoubtedly, the artist's rich and long experience was refracted and consolidated and in those pictures. In majestic epic landscapes where the point was taken "from above", the wideness and diversity of spatial plans are emphasized in our mind's eye.

\section{CONCLUSION}

The artist's creative work is multifaceted and diverse. The national originality, poetry, inner harmony, wealth of image composition comprise the main features of his art. In his works, Zverkov organically combines the life specificity with inexhaustible spirituality, personal impressions with general phenomena, and national traditions with highest skills. He creates the extremely wide image of Russia showing its nature with such tenderness and excitement that rarely can be seen in the legacy of great artists. Filled with contemplations about high ethical and moral art criteria Zverkov's creative work is not only lyrical but is wider and deeper than just thinking about the Age. The historical value of his art legacy is also that in his works he combines the landscape painting of the twentieth century with art of the twenty-first century. The meaning of his landscapes is extremely deep, and each new generation will have its own new vision of them; and that is the paramount significance of his art.

\section{REFERENCES}

[1] O.R. Nikoulina, Nature through the eyes of artists. Development challenges in modern landscape painting. M.: Soviet Artist, 1982. 175 p., 21 il., p. 54

[2] A.V. Paramonov, S.M. Charvonnaya, Soviet Painting: Book of Teacher. M. : Education, 1981-272 p., il., p. 247.

[3] I. Filonovich, Yefrem Zverkov. The Album. L.: Soviet Artist, 1978.

[4] V.S. Manin, Yefrem Zverkov. The Album. M., 2007.

[5] A.V. Paramonov, S.M. Charvonnaya, p. 246.

[6] L.V. Posadskaya, Yefrem Zverkov. The Album, M. : The White City, 2006. -48 p.; il. 